\title{
Species of Bursaphelenchus Fuchs, 1937 (Nematoda: Parasitaphelenchidae) and other nematode genera associated with insects from Pinus pinaster in Portugal
}

\author{
A.C. Penas ${ }^{1}$, M.A. Bravo ${ }^{1}$, P. Naves ${ }^{2}$, L. Bonifácio², E. Sousa ${ }^{2}$ \& M. Mota ${ }^{3}$ \\ 1 Departamento de Protecção das Plantas, Estação Agronómica Nacional (EAN), INIA, Quinta do Marquês, $2784-505$ Oeiras, Portugal \\ 2 Departamento de Protecção Florestal, Estação Florestal Nacional (EFN), INIA, Quinta do Marquês, 2784-505 Oeiras, Portugal \\ 3 NemaLab/ICAM, Departamento de Biologia, Universidade de Évora, 7002-554 Évora, Portugal
}

\section{Keywords}

Bursaphelenchus spp.; insects; Pinus pinaster; Portugal; vectors.

\author{
Correspondence \\ A.C. Penas, Estação Agronómica Nacional, \\ Protecção das Plantas, \\ 2784-505 Oeiras, Portugal. \\ E-mail: acgpenas@yahoo.com.br
}

Received: 30 June 2005; revised version accepted: 23 January 2006.

doi:10.1111/j.1744-7348.2006.00042.x

\begin{abstract}
Insects associated with maritime pine, Pinus pinaster, in Portugal were collected and screened for the presence of Bursaphelenchus species. Nematodes were identified using Internal Transcribed Spacers-Restriction Fragment Length Polymorphism (ITS-RFLP) analysis of dauer juveniles and morphological identification of adults that developed from dauer juveniles on fungal cultures or on cultures in pine wood segments at $26^{\circ} \mathrm{C}$. Several associations are described: Bursaphelenchus teratospicularis and Bursaphelenchus sexdentati are associated with Orthotomicus erosus; Bursaphelenchus tusciae, B. sexdentati and/or Bursaphelenchus pinophilus with Hylurgus ligniperda and Bursaphelenchus hellenicus with Tomicus piniperda, Ips sexdentatus and H. ligniperda. An unidentified Bursaphelenchus species is vectored by Hylobius sp. The previously reported association of Bursaphelenchus xylophilus with Monochamus galloprovincialis was confirmed. The association of Bursaphelenchus leoni with Pityogenes sp. is not definitively established and needs further studies for clarification. Other nematode genera besides Bursaphelenchus were found to be associated with the insects sampled, including two different species of Ektaphelenchus, Parasitorhabditis sp., Parasitaphelenchus sp., Contortylenchus sp. and other unidentified nematodes. The Ektaphelenchus species found in O.erosus is morphologically similar to $B$. teratospicularis found in the same insect; adults of both the species are found in cocoon-like structures under the elytra of the insects.
\end{abstract}

\section{Introduction}

Approximately one third of the nematodes belonging to the order Aphelenchida Siddiqi, 1980 are associated with insects (Poinar, 1983). These nematodes establish a variety of associations with the insects, which may be described as commensalism, e.g. phoresy (to the benefit of the nematode but not affecting the insect), mutualism (both the organisms benefit) or parasitism (nematodes benefit at the expense of the insect) (Giblin-Davis, 2004).

Most Bursaphelenchus Fuchs, 1937 species are mycetophagous, feeding on fungi in the galleries of bark beetles and thus benefit from being transported by the insects from an area of diminished resources to a more favourable locality (phoresy) (Giblin, 1985). However, Bursaphelenchus xylophilus (Steiner \& Bührer, 1934) Nickle, 1970 (the causal agent of pine wilt disease) and Bursaphelenchus cocophilus (Cobb, 1919) Baujard, 1989 (the causal agent of red ring disease of coconut) are, potentially, cases of mutualism between nematode and insect populations (Giblin-Davis, 2004). Bursaphelenchus xylophilus is transported from host to host by their vectors, Monochamus spp. (for a complete review on this subject, see Ryss et al., 2005) and B. cocophilus by Rhynchophorus palmarum (Dean, 1979; Griffith, 1987), damaging their host plants and therefore creating new breeding sites suitable for vector reproduction and proliferation 
(Mamiya, 1983; Giblin, 1985; Giblin-Davis, 1993). These two nematode species have developed the ability to parasitise plants, being capable of feeding on plant host epithelial cells and probably evolving from phoretically transmitted mycetophagous ancestors (Giblin-Davis et al., 2003).

Although not all associations between Bursaphelenchus species and insects are known, most of the species are vectored by insects belonging to the families Scolytidae, Cerambycidae and Curculionidae (Ryss et al., 2005).

To survive environmental stresses during transportation (e.g. starvation and/or desiccation), Bursaphelenchus spp., like other nematodes, have a specialised dispersal juvenile form, called the dauer juvenile. The dauer juvenile is morphologically and physiologically distinct from the other juvenile stages and is resistant to adverse conditions, allowing the nematode to invade and survive in the insect vector until it reaches a new host plant (Fuchs, 1915; Poinar, 1983). Dauer juveniles have a dome-shaped head, a vestigial stylet (or may lack this structure), a degenerate oesophagus and oesophageal glands, a poorly delimited median bulb and a subcylindrical tail with digitate terminus. These morphological features, coupled with the fact that the body is filled with stored lipids, allow easy differentiation of the dauer stage (Hunt, 1993). Dauer juveniles can be the third juvenile stage in some species (e.g. Bursaphelenchus seani, Bursaphelenchus kevini, B. cocophilus) (Giblin \& Kaya, 1983; Giblin et al.; 1984, Gerber et al., 1989) or the fourth stage juvenile in others (e.g. B. xylophilus, Bursaphelenchus mucronatus, Bursaphelenchus conicaudatus) (Mamiya, 1975; Mamiya \& Enda, 1979; Kanzaki \& Futai, 2001).

Bursaphelenchus spp. can be ectophoretic, carried from tree to tree on the insect body, in the tracheae or beneath the wings or elytra of the beetle vector, or may be endophoretic and carried in the reproductive tract or haemocoel of the vector. For example, Bursaphelenchus abietinus was found under the wings of Pityokteines spinidens, P. curvidens and P. vorontzowi (Braasch $\&$ Schmutzenhofer, 2000), and Bursaphelenchus hylobianum in the haemocoel of Hylobius albosparsus (Korenchenko, 1980).

Since the first report in Portugal and in Europe of the quarantine pathogen B.xylophilus (Mota et al., 1999), intensive annual surveys under a National Programme of Pinewood Nematode Control [Programa Nacional de Luta contra o Nemátode do Pinheiro (PROLUNP)—http:// www.dgf.min-agricultura.pt/prolunp/html/home-final.htm] have been carried out to monitor the spread of B. xylophilus and to determine its dispersal and its vectors. B. xylophilus is confined to the Setúbal peninsula and the surrounding areas-the affected zone, and Monochamus galloprovincialis Olivier was found to be its vector (Sousa et al., 2001). Besides B. xylophilus, other Bursaphelenchus species in Portugal have been found to be associated with Pinus pinaster Aiton (Sousa et al., 2002; Penas et al., 2004).

The purpose of this study was to identify the insect vectors of Bursaphelenchus spp. associated with P. pinaster in Portugal and to identify other nematode genera that are associated with the vectors. This will help determine whether these Bursaphelenchus species represent a potential risk to the forests.

\section{Materials and methods}

Insect sampling and nematode isolation

Bark- and wood-boring insects belonging mainly to the families Cerambycidae, Scolytidae, Buprestidae and Curculionidae (Coleoptera) were captured between 1999 and 2004 from six different localities in Portugal (Fig. 1) and were screened for the presence of Bursaphelenchus species.

Three methods were used to obtain the adult insects. The first method consisted of collecting the insects from $P$. pinaster trees displaying symptoms of decline (between 1999 and 2004), mainly from the affected zone and also from the north-western Portugal. Pine trees were cut and divided into logs. Some of the logs were debarked and all the adult insects were collected, while the remaining logs were kept in boxes at room temperature to allow insect emergence. Because of the presence of B. xylophilus, a more intensive survey was required in the area affected by this species and two additional methods were used for insect collection: trap trees and flight traps. Trap trees (2003-04) consisted of healthy trees that were felled and divided into logs, sprayed with $70 \%$ ethanol to attract insects and left for 1 month in the field. After 1 month, some of the logs were caged and left at room temperature to allow insect emergence, while the remaining were debarked to collect the insects. Flight traps (2003-04) were installed on P. pinaster trees and baited with terpentine and ethanol.

All the adult insects collected were identified in the laboratory to species or genus level. To determine the presence of nematodes, the insects were placed individually in a Syracuse dish in a small amount of water. First, the elytra and the wings were opened and observed and then the insect was crushed and left in water for few hours at room temperature. All the nematodes resembling Bursaphelenchus dauer juveniles were collected for species identification.

\section{Molecular identification}

Whenever possible, dauer juvenile identification was made using ITS-RFLP analysis as morphological and biometrical identification of these juvenile forms to the species level is extremely challenging. 


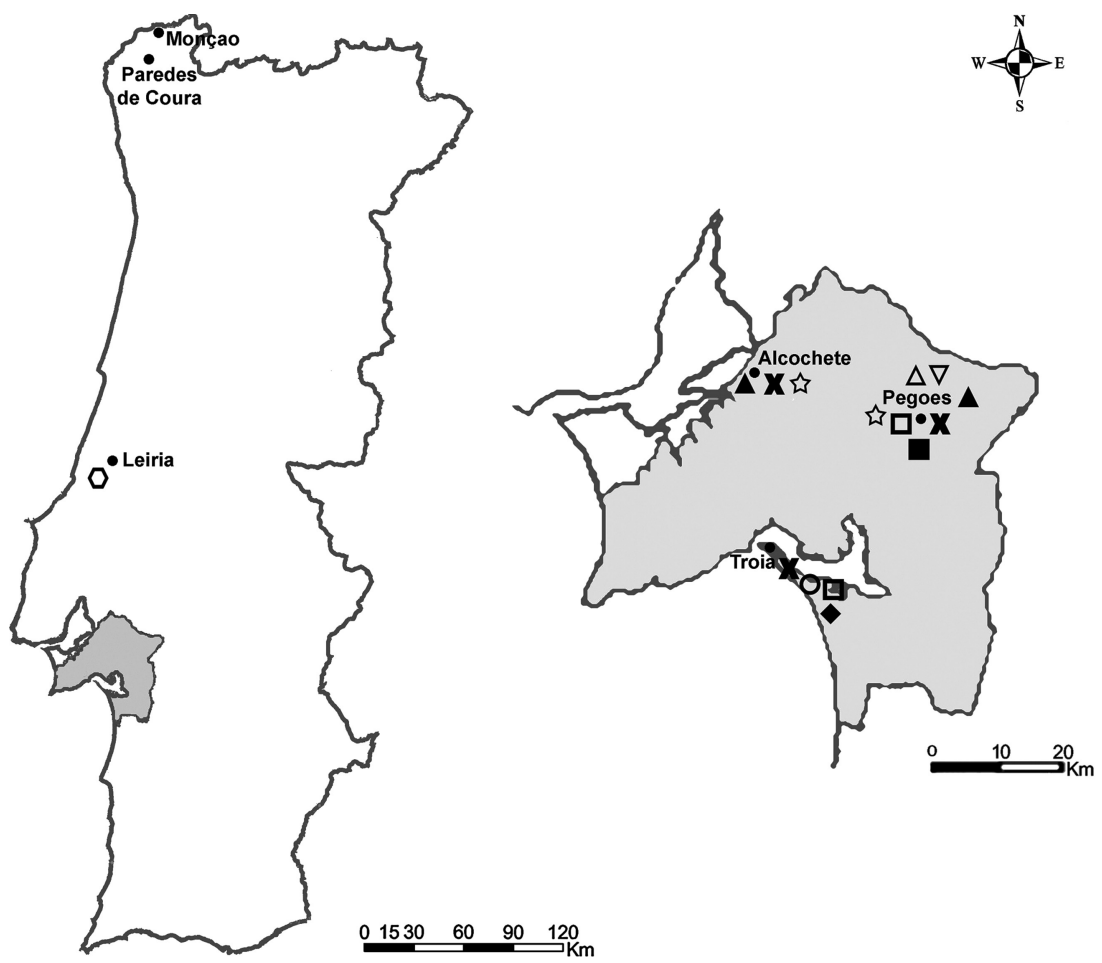

Figure 1 Sampling sites $(\bullet)$ and distribution of Bursaphelenchus-insect associations. $\square$ : region affected by B. xylophilus. Associations: Bursaphelenchus sp.-Hylobius sp. ( $(\square)$; B. xylophilus-M. galloprovincialis (x); B. teratospicularis-O. erosus (O); B. sexdentati-O. erosus ( $\square$ ); B. sexdentatilB. pinophilus-H. ligniperda $(\square$; B. hellenicus-T. piniperda $(\Delta)$; B. hellenicus-I. sexdentatus $(\nabla)$; B. hellenicus-H. ligniperda $(\mathbf{\Delta})$; B. tusciae-H. ligniperda (河) and B. leoni-H. ligniperda (

ITS-RFLP identification of dauer juveniles was made using at least five nematodes collected from the same insect. The procedure used for DNA extraction and PCR was as described in the study by Penas et al. (2004). Amplification of Internal Transcribed Spacer (ITS) regions of rDNA was performed using primers F194 and P5368 as described by Ferris et al. (1993) and Vrain (1993), respectively. Following PCR, $5 \mu \mathrm{L}$ of the amplified sample was analysed in a $1 \%$ agarose gel and DNA fragments were visualised by staining in $1 \mu \mathrm{g} \mathrm{mL}^{-1}$ of ethidium bromide. Data analysis was performed using the Versa doc analysis system. Amplified DNA was digested for at least $3 \mathrm{~h}$ at $37^{\circ} \mathrm{C}$ using $10 \mathrm{U}$ of each of the five enzymes (RsaI, HaeIII, MspI, HinfI and AluI) (Amersham BioSiences ${ }^{\circledR}$, Uppsala, Sweden) following the manufacturer's instructions. These five restriction enzymes are known to generate species-specific ITS-RFLP profiles (Burgermeister et al., 2005). The restriction fragments were resolved by electrophoresis in a $2 \%$ agarose gel, stained with ethidium bromide and analysed as described above.

\section{Morphological identification}

For species morphological identification, three different methods were used to obtain adults from the collected dauer juveniles: inoculation and incubation of juveniles in branches of $P$. pinaster and/or in fungal cultures (Monilinia fructicola or nonsporulating Botrytis cinerea) and incubation of dauer juveniles in water. For inoculation of dauer juveniles on wood, $P$. pinaster branches were cut into segments approximately $13 \mathrm{~cm}$ in length and 3-4 cm in diameter and sealed at both ends with paraffin. The juveniles were suspended in $0.2 \mathrm{~mL}$ of water and inoculated with a syringe into an orifice made in the middle of the wood segment. The orifices were sealed with paraffin and the segments were enclosed in the sealed plastic bags and stored at $26 \pm 2{ }^{\circ} \mathrm{C}$ for 4 weeks. Some segments of the same branches were kept under the same conditions, without inoculation and used as control to ensure absence of previous infestation with Bursaphelenchus spp.. After this period, the segments were cut into $3-\mathrm{mm}$ discs and the nematodes were extracted using the Baermann funnel technique for $48 \mathrm{~h}$. The second method to allow the dauer juveniles to develop into adult stage used fungal cultures. The juveniles were suspended in $0.1 \mathrm{~mL}$ of water, inoculated with a micropipette into a Petri dish containing a fungal culture and incubated at $26^{\circ} \mathrm{C}$ for 3 weeks. The nematodes were extracted using a modified Baermann funnel 
technique for $24 \mathrm{~h}$. For the last method, the dauer juveniles were maintained in water at $26^{\circ} \mathrm{C}$ and their development was observed daily. This last method allowed the developmental stage of dauer juveniles (third or fourth) to be determined by observation of the developmental stage obtained after the first molt. The adult nematodes obtained from all methods were identified in temporary mounts using an Olympus BX51 (Hamburg, Germany) light microscope and scanning electron microscope (SEM) observations. For SEM studies, the nematodes were prepared as described by Eisenback (1985) and observed in a JEOL 35 SEM. Several characteristics were used for Bursaphelenchus species identification including spicule shape, vulval region, number and disposition of caudal papillae, female tail and number of lateral lines. The identification method used depended on the abundance and condition of the juveniles obtained from each insect.

Other nematode genera were mounted on temporary slides, observed and identified under the light microscope.

\section{Results}

\section{Bursaphelenchus spp.-insect associations}

A total of 3294 insects belonging to 22 different species were collected and screened for the presence of Bursaphelenchus nematodes during this survey (Table 1); 2400 insects emerged from symptomatic $P$. pinaster trees, 668

Table 1 Insects screened for the presence of Bursaphelenchus species between 1999 and 2004

\begin{tabular}{|c|c|c|c|}
\hline Family/Species & $\begin{array}{l}\text { Observed } \\
\text { Insects }(n)\end{array}$ & $\begin{array}{l}\text { Insects with } \\
\text { Bursaphelenchus } \\
\text { Dauer Juveniles (\%) }\end{array}$ & $\begin{array}{l}\text { Bursaphelenchus } \\
\text { Species Associated }\end{array}$ \\
\hline \multicolumn{4}{|l|}{ Coleoptera } \\
\hline \multicolumn{4}{|l|}{ Cerambycidae } \\
\hline Monochamus galloprovincialis ${ }^{a}$ & 541 & 20 & Bursaphelenchus xylophilus \\
\hline Arhopalus ferus & 26 & 0 & - \\
\hline Arhopalus syriacus & 80 & 0 & - \\
\hline Pogonocherus perroudi & 55 & 0 & - \\
\hline Acanthocinus griseus & 78 & 0 & - \\
\hline Spondylis buprestoides & 13 & 0 & - \\
\hline Rhagium inquisitor & 3 & 0 & - \\
\hline Ergates faber & 1 & 0 & - \\
\hline \multicolumn{4}{|l|}{ Scolytidae } \\
\hline Orthotomicus erosus & 899 & 19 & $\begin{array}{l}\text { Bursaphelenchus teratospicularis } \\
\text { Bursaphelenchus sexdentati }\end{array}$ \\
\hline Tomicus piniperda & 168 & 24 & Bursaphelenchus hellenicus \\
\hline Ips sexdentatus & 300 & 19 & B. hellenicus \\
\hline Hylurgus ligniperda & 557 & 5 & $\begin{array}{l}\text { Bursaphelenchus tusciae } \\
\text { B. hellenicus } \\
\text { Bursaphelenchus sexdentati and/or Bursaphelenchus pinophilus }\end{array}$ \\
\hline Pityogenes sp. & 175 & 2 & Bursaphelenchus leonic ${ }^{\mathrm{C}}$ \\
\hline Hylastes sp. & 34 & 0 & - \\
\hline \multicolumn{4}{|l|}{ Buprestidae } \\
\hline Crysobothris solieri & 50 & 0 & \\
\hline Calcophora mariana & 11 & 0 & - \\
\hline Phaenops cyanea & 3 & 0 & - \\
\hline \multicolumn{4}{|l|}{ Curculionidae } \\
\hline Pissodes castaneus & 177 & 2 & - \\
\hline Eremotes porcatus & 50 & 2 & - \\
\hline Hylobius sp. & 62 & 14 & Bursaphelenchus sp. \\
\hline \multicolumn{4}{|l|}{ Elateridae } \\
\hline Unidentified sp. & 10 & 0 & - \\
\hline \multicolumn{4}{|l|}{ Hymenoptera } \\
\hline \multicolumn{4}{|l|}{ Siricidae } \\
\hline Sirex noctilio & 1 & 0 & - \\
\hline Total & 3294 & 13 & - \\
\hline
\end{tabular}

${ }^{a}$ Only collected from the affected zone.

${ }^{b}$ Only differentiated by molecular methods.

${ }^{\mathrm{c}}$ Association not definitively established. 
insects were obtained from trap trees and 226 insects were captured in flight traps. Most of the Bursaphelenchus spp. were found to be associated with insects of the family Scolytidae. Nine insect species were found carrying Bursaphelenchus dauer juveniles (Table 1; Fig. 1).

Bursaphelenchus xylophilus was only found associated with M. galloprovincialis. No other nematodes were found in the M. galloprovincialis specimens observed. Bursaphelenchus teratospicularis Kakuliya \& Devdariani, 1965 and Bursaphelenchus sexdentati Rühm, 1960 were found associated with Orthotomicus erosus Wollaston (Figs 2 and 3); B. sexdentati and/or Bursaphelenchus pinophilus Brzeski \& Baujard, 1997 with Hylurgus ligniperda F.; an unidentified Bursaphelenchus sp. with Hylobius sp. (Fig. 4); Bursaphelenchus tusciae Ambrogioni \& Palmisano, 1998 with
H. ligniperda and Bursaphelenchus hellenicus Braasch \& Michalopoulou, 1998 with Tomicus piniperda L., Ips sexdentatus Boern and H. ligniperda (Fig. 5). Bursaphelenchus leoni Baujard, 1980 was only found once, a single male in the sawdust attached to one Pityogenes sp.

\section{Dauer location in the insects}

With the exception of B.xylophilus, which was found packed in the tracheae of its vector, and Bursaphelenchus sp., that was found within the insect body, all other Bursaphelenchus dauer juveniles were found under the elytra and wings, between the folds of the insect body and on the insect's hairs (Fig. 6).
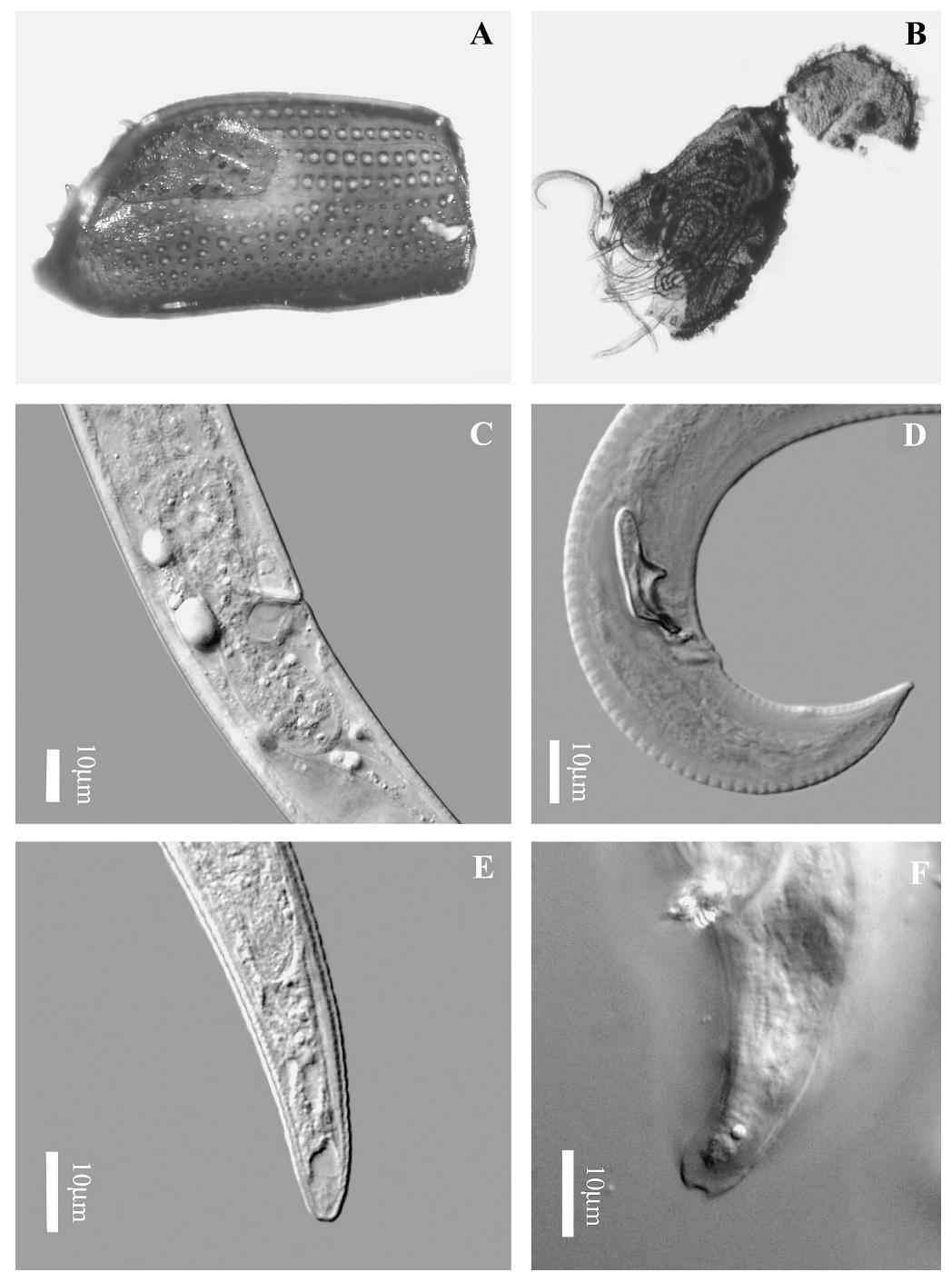

Figure 2 Adults of Bursaphelenchus teratospicularis associated with Orthotomicus erosus. (a) light micrograph (LM) of cocoon under the elytra, (b) cocoon with adults inside (LM), (c) vulval region (LM), (d) male tail (LM), (e) female tail (LM), (f) bursa on male tail tip (LM). 


\section{Dauer description and abundance}

Bursaphelenchus spp. dauer juveniles found associated with these insects were morphologically very similar, with a dome-shaped head, an indistinct stylet, a poorly defined median bulb and anterior lip region and an elongated conoid tail, with the terminus mucronate, digitate or pointed. With the exception of B. xylophilus, which had a body length of 500-600 $\mu \mathrm{m}$, all the collected species had a similar body length $(400-500 \mu \mathrm{m})$. These juveniles displayed slow movements and survived for a few days in water.

The number of Bursaphelenchus dauer juveniles was low in most cases, usually between 10-100 per insect, only exceptionally reaching some hundreds of nematodes. However, B. xylophilus was occasionally found in high numbers (thousands) in the tracheal system of its vector.

\section{Molecular identification}

ITS-RFLP analysis of the dauer juveniles found in $O$. erosus originated a restriction pattern similar to B. sexdentati, after comparison with reference patterns established by Burgermeister et al. (2005) (Fig. 3). Dauer juveniles collected from other $O$. erosus, H. ligniperda and I. sexdentatus specimens were analysed using this method, but no successful results were obtained.

\section{Morphological identification}

With the exception of the B. leoni-Pityogenes sp. association, the diagnosis of the remaining associations was made based on the morphological identification of the adults obtained from successful inoculations of dauer juveniles on segments of pine branches or on the fungal cultures. No Bursaphelenchus species were collected from the pine branches used as controls.

Dauer juvenile development in water was successfully observed for B.xylophilus and B. hellenicus. B. xylophilus dauer juveniles molted directly to the adult stage and dauer of B. hellenicus molted first to the fourth juvenile stage (propagative form) and only later to the adult stage. In the case of B. xylophilus, about $25-50 \%$ of the dauer juveniles developed to the adult stage (females and males) after $72 \mathrm{~h}$ at $26^{\circ} \mathrm{C}$. B. hellenicus dauer juveniles molted to the fourth juvenile stage after $120 \mathrm{~h}$, and subsequently, very few reached the adult stages after 240 h (Fig. 5). In two H. ligniperda individuals, adults of $B$. hellenicus were found mixed with the dauer juveniles.

Adults of B. teratospicularis were found in one cocoonlike structure beneath the elytra of one O. erosus; this cocoon contained 25 adults comprised of 3 males and 22 females.

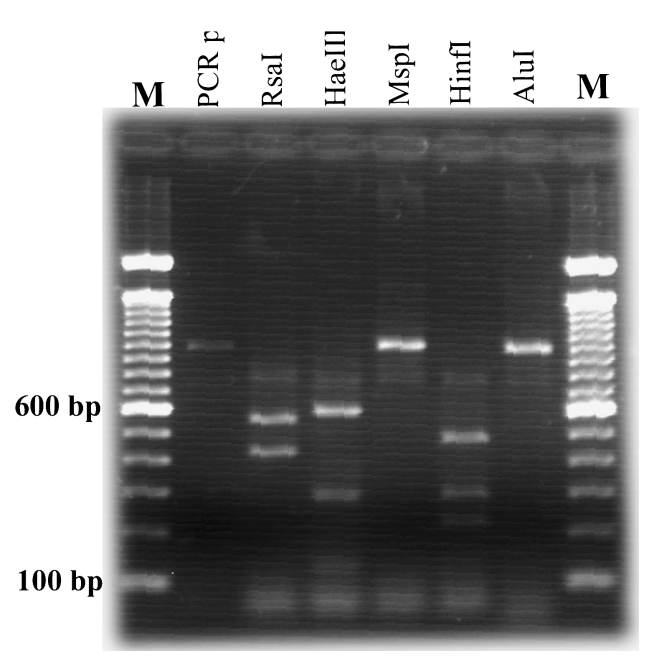

Figure 3 ITS-RFLP pattern of dauer juveniles of Bursaphelenchus sexdentati associated with Orthotomicus erosus.

In addition to the nematodes described above, Bursaphelenchus dauer juveniles were collected from O. erosus, T. piniperdae, I. sexdentatus, H. ligniperda, Pityogenes sp., Pissodes castaneus and Eremotes porcatus, which could not be identified.

\section{Other nematode genera associations with insects}

Other nematode genera were found associated with 9 of the 22 insect species observed (Table 2; Fig. 7). O. erosus and H. ligniperda carried two different Ektaphelenchus

Table 2 Other nematode genera associated with the 3294 insects observed

\begin{tabular}{ll}
\hline Nematode Genus & Insect Infested with Nematodes (\%) \\
\hline Ektaphelenchus sp.A & Orthotomicus erosus (3) \\
Ektaphelenchus sp.B & Hylurgus ligniperda (7) \\
Parasitaphelenchus spp. & Ips sexdentatus (23) \\
H. ligniperda (5) \\
O. erosus (20) \\
Tomicus piniperda (1) \\
I. sexdentatus (33) \\
H. ligniperda (10) \\
O. erosus (22) \\
I. sexdentatus (9) \\
H. ligniperda (5) \\
O. erosus (16) \\
T. piniperda (9) \\
I. Sexdentatus (42) \\
H. ligniperda (38) \\
Pissodes castaneus (6) \\
Eremotes porcatus (10) \\
Hylobius sp. (26)
\end{tabular}



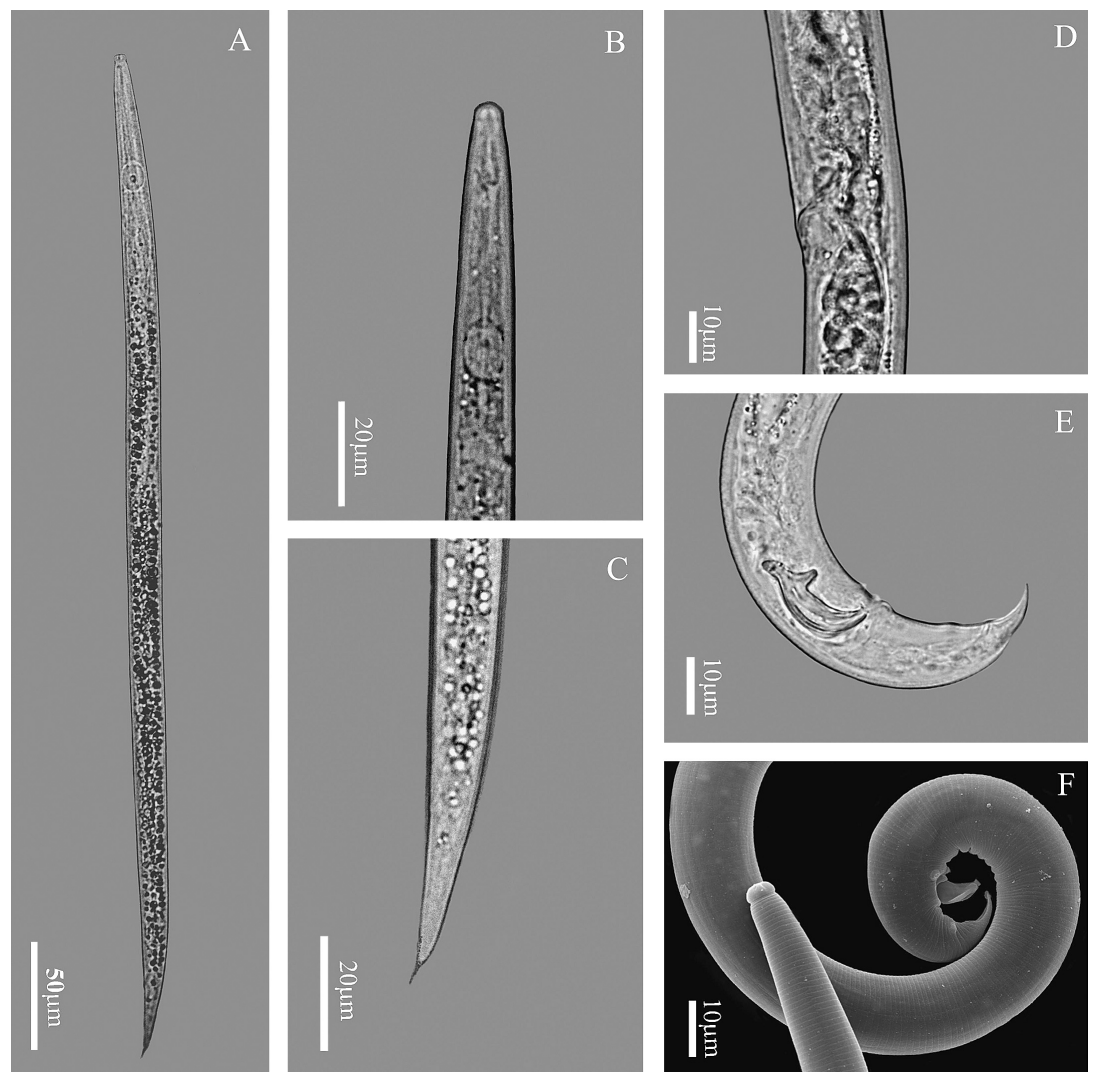

Figure 4 Bursaphelenchus sp. associated with Hylobius sp. Dauer juveniles isolated from the insect (a-c). (a) light micrograph (LM) of dauer juvenile, (b) anterior region (LM), (c) tail (LM). Adults obtained from pine branches inoculated with dauer juveniles (d-f), (d) vulval region (LM), (e) male tail (LM), (f) scanning electron micrograph of male.

species in cocoon-like structures under the elytra. In both cases, only immature, inseminated females were found, varying in numbers from 10 to 50 per insect (Fig. 7a-7d). Juveniles of the genus Parasitorhabditis (Fig. 7g), internal parasites of bark beetles (Massey, 1974), were found in the gut of $O$. erosus, T. piniperdae, I. sexdentatus and H. ligniperda; these juveniles moved quickly and constantly in water and are characterised by their distinct cuticle annulations in the anterior region, very slender body and an elongated conoid tail that was pointed to the extent that it was almost filiform. Other juveniles, of the genus Parasitaphelenchus (Fig. 7e), were found in the haemocoel of I. sexdentatus and H. ligniperda. These juveniles appeared in low numbers $(<100)$ and were slender and of medium size, with the body narrowing sharply towards the head and less sharply towards the tail. The lip region of these nematodes was rounded, continuous with the body contour and had a typical hook projection, while the tail was rounded, narrowing and had a short sharp mucron. O. erosus, I. sexdentatus and $H$. ligniperda were found associated with nematodes of the genus Contortylenchus (Fig. 7f). Hundreds of eggs and juveniles of this genus were present in the body haemocoel, and several females ( $>10$ per beetle) were seen to occur together in the insect body. No males were recovered from the body cavity of the insects. Juveniles of different sizes were present, which had a very thin cuticle. These juveniles collapsed rapidly when removed from the insect to the water as a result of the differential pressure. Other nematode genera were found associated with the collected insects, but their identification was not possible (Fig. 7h and Fig. 7i).

\section{Discussion}

This study corroborates preliminary results for Portugal (Sousa et al., 2002) and also confirms that one insect species can vector several Bursaphelenchus species (e.g. $O$. erosus and H. ligniperda; Table 1). Likewise, it was shown that the same Bursaphelenchus species can have different insect vectors (e.g. B. hellenicus; Table 1), confirming previous observations for this genus (Braasch, 2001; Ryss et al., 2005). This suggests a nonspecialised relationship between Bursaphelenchus spp. and their 

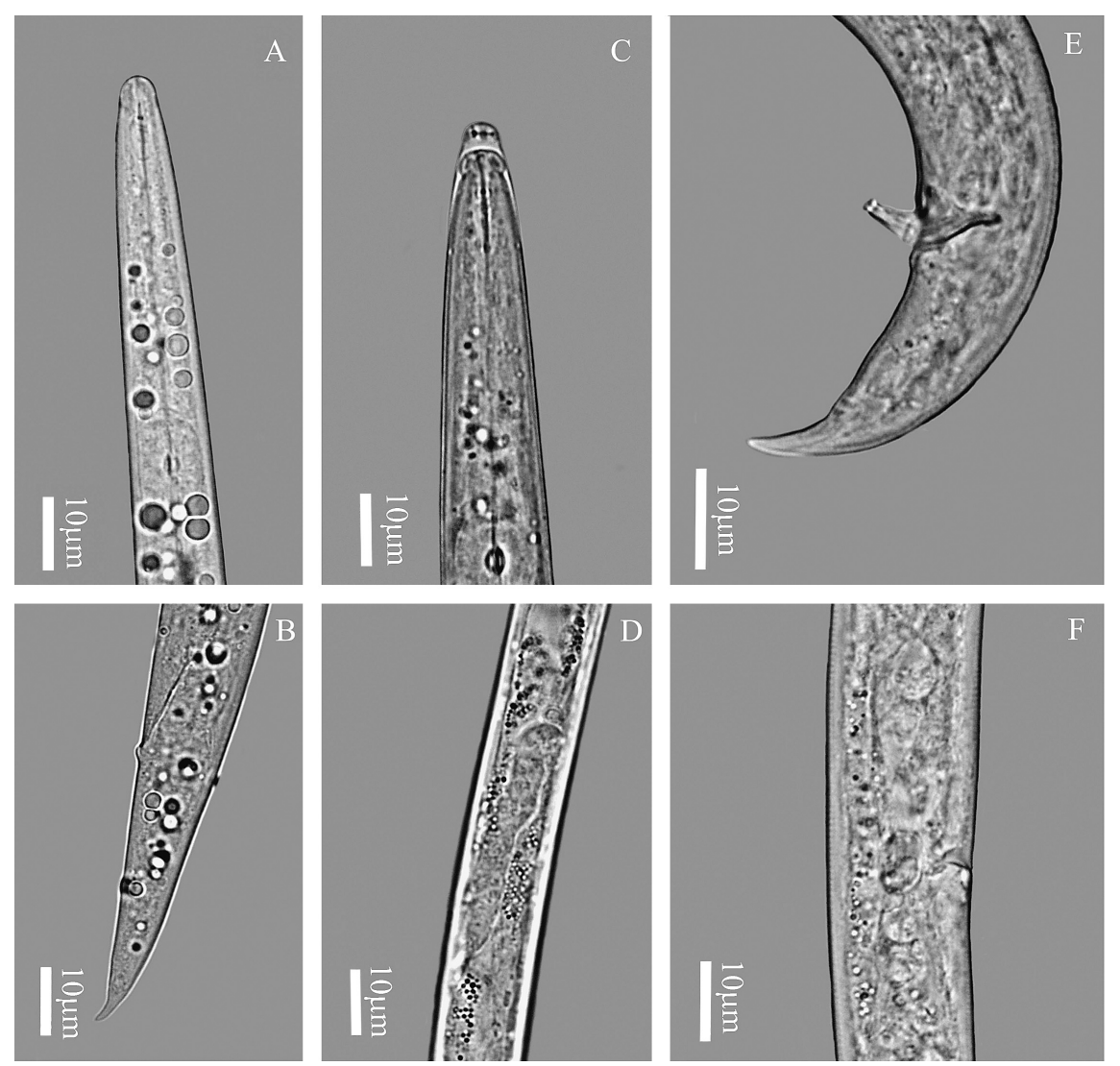

Figure 5 Bursaphelenchus hellenicus associated with Hylurgus ligniperda. (a) light micrograph (LM) of dauer juvenile anterior region, (b) tail of dauer juvenile (LM), (c) molt of dauer juvenile to fourth propagative juvenile (LM), (d) gonad of fourth juvenile stage (LM), (e) male tail (LM), (f) vulval region (LM).

vectors. However, in Portugal, B. xylophilus may have a close and specialised relationship with M. galloprovincialis as this nematode species was not found in any other insect and M. galloprovincialis was not associated with any nematode species other than B. xylophilus. An association between B. mucronatus and M. galloprovincialis has been reported in several European countries
(Magnusson \& Schroeder, 1989; Tomminen et al., 1989; Palmisano et al., 1992; Braasch et al., 1999). However, this association was not found in Portugal, despite the high number of Monochamus observed. This may be because that the observed Monochamus originated from the affected zone where B. xylophilus occurrence may have suppressed B. mucronatus dispersion. Moreover, even
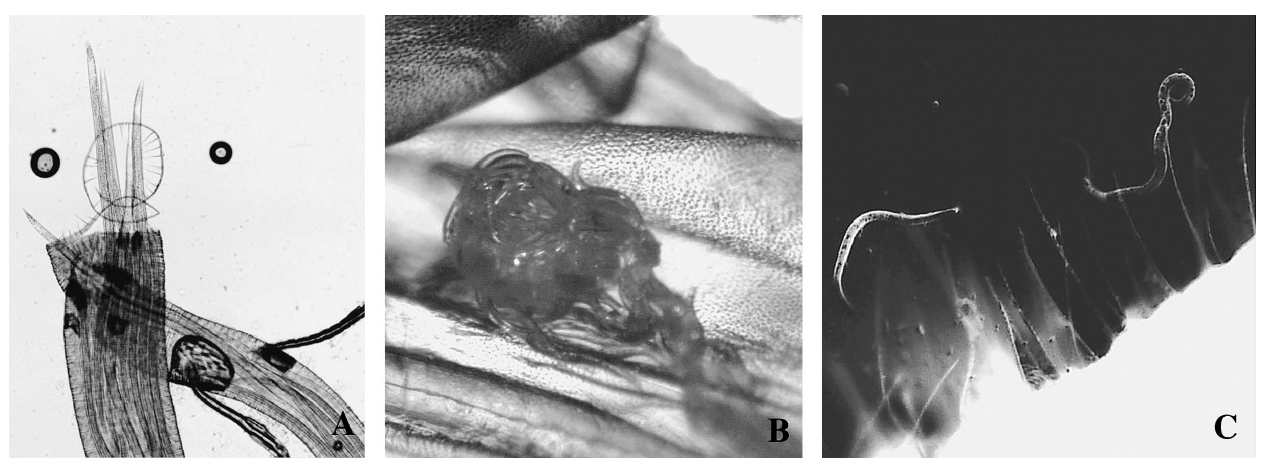

Figure 6 (a) Bursaphelenchus xylophilus inside the tracheae of Monochamus galloprovincialis, (b) Bursaphelenchus dauer juveniles on Ips sexdentatus wings, (c) Bursaphelenchus dauer juveniles on Ips sexdentatus hair. 
outwith the affected zone, B. mucronatus does not occur frequently, being only found in one sample (Penas et al., 2004). Curiously, one of the species, Bursaphelenchus sp.1 (Penas et al., 2004), most frequently found in maritime pine in Portugal in a previous study was not found in this study. It is possible that this species is vectorised by an unsurveyed insect belonging to a distinct family of xylophagous Coleoptera, like Bostrychidae or Anobiidae, or even by insects from a different order, as some Bursaphelenchus spp. are associated with Hymenoptera and Lepidoptera (Ryss et al., 2005).

Some of the associations described have been previously reported in other countries. The association between $B$. teratospicularis and insects belonging to the genus Orthotomicus has been previously reported (Kakuliya $\&$
Devdariani, 1965); B. hellenicus has formerly been associated with T. piniperda (Braasch et al., 2000). The following phoretic associations: B. hellenicus-I. sexdentatus, B. hellenicus-H. ligniperda, B. sexdentati-O. erosus, B. sexdentati-H. ligniperda and B. tusciae-H. ligniperda have never been previously reported. Bursaphelenchus sp., which is associated with Hylobius sp., was previously identified as B. hylobianum Korenchenko, 1980 (Penas et al., 2004), but further molecular and biological studies contradict this identification.

The presence of the adults of B. hellenicus found in two $H$. ligniperda specimens together with the dauer juveniles of the same species might be explained by the high temperature and moisture that the insects were exposed to during transport from the field to the laboratory.
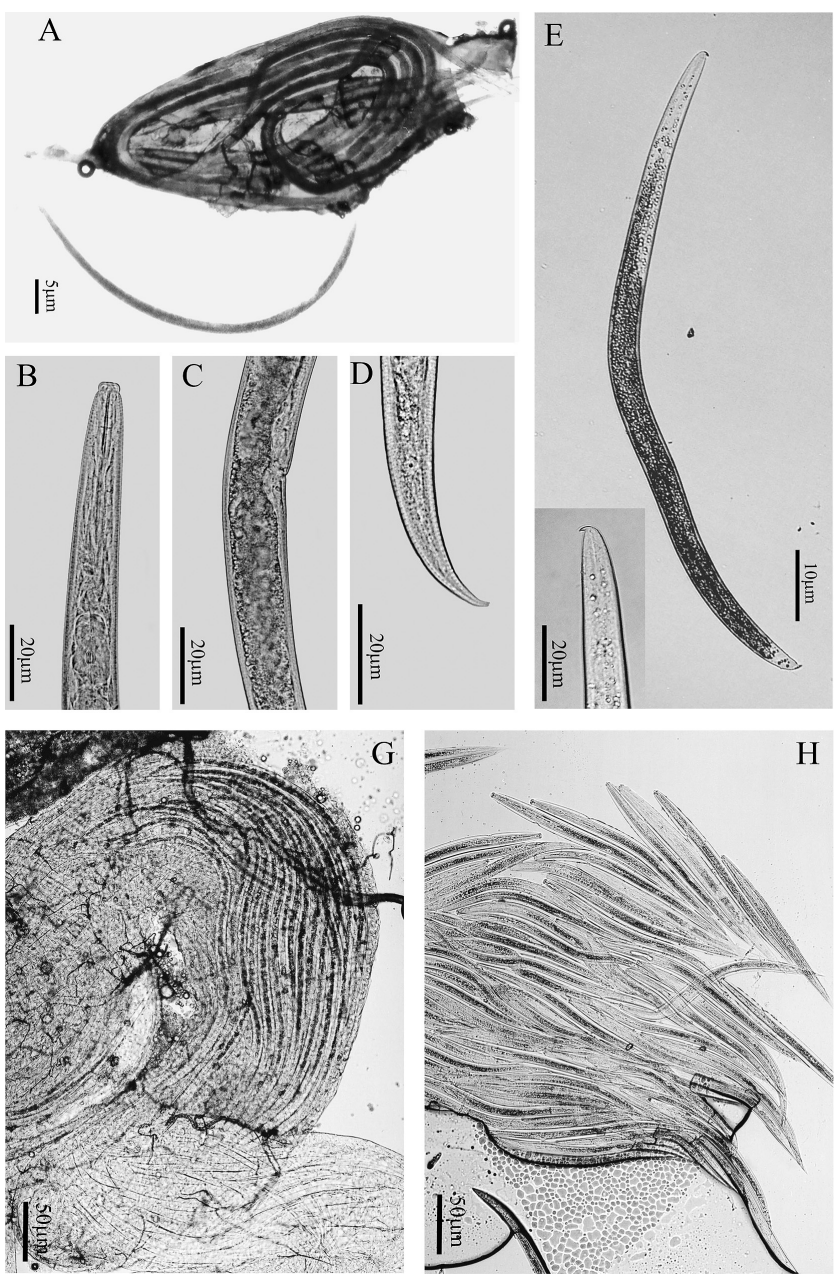

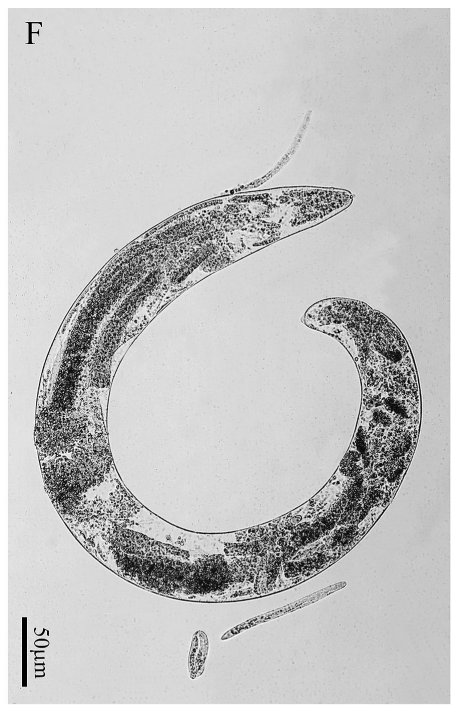

H

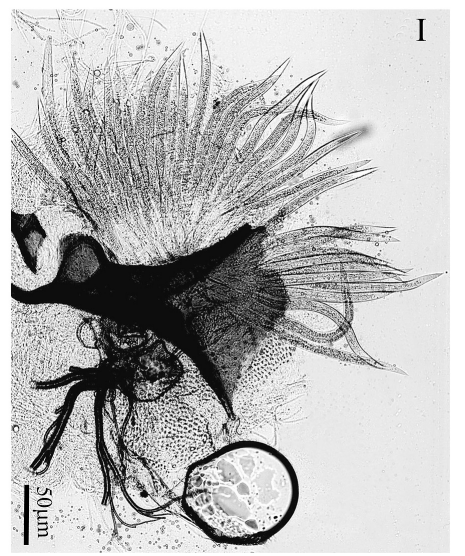

Figure 7 Other nematodes genera associated with the insects observed. Ektaphelenchus sp.2 females associated with Hylurgus ligniperda (a-d). (a) light micrograph (LM) of cocoon with females inside, (b) anterior region (LM), (c) vulval region (LM), (d) female tail (LM), (e) Parasitaphelenchus sp. (LM); inset: head (LM), (f) Contortylenchus sp. (LM), (g) Parasitorhabditis sp. within insect gut (LM), (h, i) unidentified nematode genera (LM). 
However, we have shown that two moults are required for this nematode to reach the adult stage and that the dauer juvenile stage is the third stage.

The hypothesis that Pityogenes sp. is a vector of $B$. leoni requires confirmation because only one male was observed in the sawdust attached to the insect. B. leoni is difficult to multiply and to maintain under controlled conditions, and even if B. leoni dauer juveniles were obtained, it would be difficult to obtain adults for identification. This nematode may therefore be underrepresented in our analysis.

Given this, and similar problems in obtaining adult nematodes from dauer juveniles, we aimed to use molecular methods for identification from dauer stages wherever possible. However, ITS-RFLP patterns of dauer juveniles were difficult to obtain. It is possible that the high lipid content of this survival stage made obtaining DNA from the few nematodes available in a form suitable for PCR amplification problematic.

Bursaphelenchus teratospicularis may have an affinity with nematodes belonging to the genus Ektaphelenchus. Adults of this species were found in a cocoon-like structure under the elytra of O. erosus. Some Ektaphelenchus species have been reported as being transported in similar structures under the insect elytra (Thorne, 1935; Rühm, 1956; Massey, 1974). Morphologically, B. teratospicularis shares many characteristics with Ektaphelenchus. Both are characterised by a slender, mediumsized, ventrally arcuate body; a coarsely annulated cuticle; flattened cephalic region; wide and distinctly offset stylet with a long wide lumen; cylindrical procorpus joining a large, prominent, rounded-rectangular median bulb; vulva with lips not protuberant; intestine ending in a blind sac and an anus that is very difficult to discern (Hunt, 1993). Furthermore, Ektaphelenchus cocoons are described as usually containing only immature females and sporadically males (Massey, 1974). Of the B.teratospicularis adults found in 0 . erosus, 22 were females and 3 males. The presence of a terminal bursa on the male tail tip of these nematodes, absent in the genus Ektaphelenchus (Hunt, 1993), was the specific and diagnostic character used to include it in the genus Bursaphelenchus. Because of the similarities between these species to nematodes in the genus Ektaphelenchus in morphology and cocoon-forming habit, a more detailed and precise study will be required to clarify their taxonomic status.

This work is a contribution to the knowledge on the distribution and biology of the genus Bursaphelenchus in Portugal and Europe. More knowledge on the biology of Bursaphelenchus species and about the interactions with their vectors is needed. With new Bursaphelenchus species being described from Europe, studies on these relationships as well as on the biology of vectors (e.g. number of generations per year, maturation feeding and feeding habits) will allow predictions of possible risk caused by these species to European forests.

\section{Acknowledgements}

This research was supported by grant 11 189/98 of the Portuguese PRAXIS XXI project, Fundação Ciência e Tecnologia (FCT) and PARLE D project (Instituto Nacional de Investigação Agrária-INIA and FCT) and is now currently being supported by the European Union fifth Framework, project QLK5-CT-2002-00672-PHRAME (Development of improved pest risk analysis techniques for quarantine pests, using pinewood nematode, B. xylophilus, in Portugal as a model system). This paper is a portion of the $\mathrm{PhD}$ dissertation of the first author, University of Évora, who is supported by a doctoral scholarship from FCT (BD 8920/2002). The authors kindly thank Prof. Esperança Pina, Faculdade de Ciências Biomédicas, Universidade Nova de Lisboa, for the use of the SEM; Mr Octávio Chaveiro, Estação Agronómica Nacional, for technical assistance and Prof. John Webster and Dr John Jones for reviewing this paper.

\section{References}

Braasch H. (2001) Bursaphelenchus species in conifers in Europe: distribution and morphological relationships. Bulletin OEPP/EPPO, 31, 127-142.

Braasch H., Schmutzenhofer H. (2000) Bursaphelenchus abietinus sp. n. (Nematoda: Parasitaphelenchidae) associated with fir bark beetles (Pityokteines spp.) from declining silver fir trees in Austria. Russian Journal of Nematology, 8, 1-6.

Braasch H., Metge K., Burgermeister W. (1999) Bursaphelenchus species (Nematoda, Parasitaphelenchidae) found in coniferous trees in Germany and their ITS-RFLP patterns. Nachrichtenblatt des Deutschen Pflanzenschutzdienste, 51, 312-320.

Braasch H., Burgermeister W., Harmey M.A., MichalopoulosSkarmoutsos H., Tomiczek C., Caroppo S. (2000) Pest Risk Analysis of Pinewood Nematode Related Bursaphelenchus Species in View of South European Pine Wilt and Wood Imports from Asia. Final Report of EU Research Project Fair CT 95-0083, Kleinmachnow, Germany.

Burgermeister W., Metge K., Braasch H., Buchbach E. (2005) ITS-RFLP patterns for differentiation of 26 Bursaphelenchus species (Nematoda: Parasitaphelenchidade) and observations on their distribution. Russian Journal of Nematology, 13, 29-42.

Dean C.G. (1979) Red Ring Disease of Cocos nucifera L. Caused by Rhadinaphelenchus cocophilus (Cobb, 1919) Goodey, 1960. Technical Communication no 47. St Albans, UK: Commonwealth Institute of Helminthology. 
Eisenback J. (1985) Techniques for preparing nematodes for scanning electron microscopy. In An Advanced Treatise on Meloidogyne. Volume II, pp. 79-105. Eds K.R. Barker, C.C. Carter and N.J. Sasser. Raleigh, NC: North Carolina State University Graphics.

Ferris R.V., Ferris M.J., Faghihi J. (1993) Variation in spacer ribosomal DNA in some cyst-forming species of plant parasitic nematodes. Fundamental and Applied Nematology, $16,177-184$.

Fuchs A.G. (1915) Die Naturgeschichte der Nematoden und einiger anderen Parasiten. I. Des Ips typographus L. 2. Des Hylobius abietis L. Zoologische Jahrbücher, Abteilung für Systematik, Öekologie und Geographie der Tiere, 38, 109-122.

Gerber K., Giblin-Davis R.M., Griffith R., Escobar-Goyes J., Cartaya A. (1989) Morphometric comparisons of geographic and host isolates of the red ring nematode, Rhadinaphelenchus cocophilus. Nematropica, 19, 151-159.

Giblin R.M. (1985) Association of Bursaphelenchus sp. (Nematoda: Aphelenchoididae) with nitidulid beetles (Coleoptera: Nitidulidae). Revue Nématologie, 8, 369-375.

Giblin R.M., Kaya H.K. (1983) Bursaphelenchus seani n. sp. (Nematoda: Aphelenchoididae) a phoretic associate of $A n$ thopora bomboides stanfordiana Cockerell, 1904 (Hymenoptera: Anthoporidae). Revue de Nématologie, 6, 39-50.

Giblin R.M., Swan J.L., Kaya H.K. (1984) Bursaphelenchus kevini n. sp. (Aphelenchida: Aphelenchoididae), an associate of bees in the genus Halictus (Hymenoptera: Halictidae). Revue de Nématologie, 7, 77-187.

Giblin-Davis R.M. (1993) Interactions of nematodes with insects. In Nematode Interactions, pp. 302-344. Ed M. Wajed. New York, NY: Chapman \& Hall.

Giblin-Davis R.M. (2004) Nematodes and mutualists: where and how did these associations evolve? Nematology Monographs of Perspectives, 2, 383-394.

Giblin-Davis R.M., Davies K.A., Morris K., Thomas W.K. (2003) Evolution of parasitism in insect-transmitted plant nematodes. Journal of Nematology, 35, 133-141.

Griffith R.M. (1987) Red ring disease of coconut palm. Plant Disease, 71, 193-196.

Hunt D.J. (1993) Aphelenchida, Longidoridae and Trichodoridae: Their Systematics and Bionomics. Wallingford, UK: CAB International.

Kakuliya G.A., Devdariani T.G. (1965) A new species of nematode Bursaphelenchus teratospicularis. n. sp. (Nematoda: Aphelenchoidea). Soobshcheniya Akademii Nauk Gruzinskoi SSR 38, 191-197.

Kanzaki N., Futai K. (2001) Life history of Bursaphelenchus conicaudatus (Nematoda: Aphelenchoididae) in relation to the yellow-spotted longicorn beetle, Psacothea hilaris (Coleoptera: Cerambycidae). Nematology, 3, 473-479.

Korenchenko E.A. (1980) New species of nematodes from the family Aphelenchoididae, parasites of stem pests of the Dahurian Larch. Zoologichesky Zhurnal, 59, 1768-1780.

Magnusson C., Schroeder L.M. (1989) First record of a Bursaphelenchus species (Nematoda) in Monochamus beetles in Scandinavia. Anzeiger fur Schadlingskunde Pflanzenschutz, Umweltschutz, 62, 53-54.

Mamiya Y. (1975) The life history of the pine wood nematode, Bursaphelenchus lignicolus. Japanese Journal of Nematology, 5, 16-25.

Mamiya Y. (1983) Pathology of the pine wilt disease caused by Bursaphelenchus xylophilus. Annual Review of Phytopathology, 21, 201-220.

Mamiya Y., Enda N. (1979) Bursaphelenchus mucronatus n.sp. (Nematoda: Aphelenchoididae) from pine wood and its biology and pathogenicity to pine trees. Nematologica, 25 , 353-361.

Massey C.L. (1974) Biology and Taxonomy of Nematodes Parasites and Associates of Bark Beetles in the United States. U.S. Department of Agriculture Forest Service Agriculture Handbook No 446.

Mota M., Braasch H., Bravo M.A., Penas A.C., Burgermeister W., Metge K., Sousa E. (1999) First report of Bursaphelenchus xylophilus in Portugal and in Europe. Nematology, 1, 727-734.

Palmisano A.M., Ambrogioni L., Caroppo S. (1992) Bursaphelenchus mucronatus (Nematoda: Aphelenchoididae) su Pinus pinaster in Italia. Redia, 75, 517-527.

Penas A.C., Correia P., Bravo M.A., Mota M., Tenreiro R. (2004) Species of Bursaphelenchus Fuchs, 1937 (Nematoda: Parasitaphelenchidae) associated with maritime pine in Portugal. Nematology, 6, 437-453.

Poinar G.O. Jr. (1983) The Natural History of Nematodes. Englewood Cliffs, New Jersey: Prentice Hall.

Rühm W. (1956) Die nematoden der Ipiden. Parasitologische Schriftenreihe, 6, 1-435.

Ryss A., Vieira P., Mota M., Kulinich O. (2005) A synopsis of the genus Bursaphelenchus Fuchs, 1937 (Aphelenchida: Parasitaphelenchidae) with keys to species. Nematology, 7, 393-458.

Sousa E., Bravo M.A., Pires J., Naves P., Penas A.C., Bonifácio L., Mota M. (2001) Bursaphelenchus xylophilus (Nematoda: Aphelenchoididae) associated with Monochamus galloprovincialis (Coleoptera; Cerambycidae) in Portugal. Nematology, 3, 89-91.

Sousa E., Naves P., Bonifácio L., Bravo M.A., Penas A.C., Pires J., Serrão M. (2002) Preliminary survey for insects associated with Bursaphelenchus xylophilus in Portugal. Bulletin OEPP/EPPO Bulletin, 32, 499-502.

Thorne G. (1935) Nemic parasites and associates of the mountain pine beetle (Dendroctonus monticolae) in Utah. Journal of Agricultural Research, 51, 131-144.

Tomminen J., Nuorteva M., Pulkkinen M., Vakeva J. (1989) Occurrence of the nematode Bursaphelenchus mucronatus Mamiya \& Enda 1979 (Nematoda: Aphelenchoididae) in Finland. Silva Fennica, 23, 271-277.

Vrain T. (1993) Restriction fragment length polymorphism separates species of Xiphinema americanum group. Journal of Nematology, 25, 361-364. 